\title{
The Impact of Customer Engagement in Online Reviews on the Credibility of Shopping Sites and Customer Purchase Intentions
}

\author{
Geumchan Hwang \\ Department of Human Performance and Health Education, Western Michigan University \\ 1903 W Michigan Ave, Kalamazoo, MI 49008 \\ Jinhee Yoo \\ Dahlkemper School of Business, Gannon University, 109 University Square, Erie, PA 16541
}

\begin{abstract}
Online reviews have become an important source of information when online shoppers purchase products on shopping sites. Many researchers examined how online reviews affect the credibility of website and shopper's purchase intentions. However, minimal studies have been conducted regarding how the credibility of website and purchase intentions are differently affected by the extent to which customers are engaged in online reviews. Therefore, this study aimed to examine the impact of customer engagement in online reviews on website credibility and purchase intentions. A total of 403 students completed questionnaires measuring Customer Engagement in Online Reviews, Website Credibility, and Online Purchase Intentions. One-way MANOVA was conducted to test how website credibility and online purchase intentions are affected by a level (low, medium, and high) of customer engagement in online reviews. The results of the study revealed that there were significant multivariate effects of the level of customer engagement in online reviews on website credibility and online purchase intentions. The study also found customer engagement in online reviews positively predicted website credibility, and website credibility significantly predicted online purchase intentions. This study provides online retailers and marketers with practical implications regarding relationship management through online reviews.
\end{abstract}

Keywords: Customer engagement, online reviews, website credibility, purchase intentions

DOI: $10.7176 / \mathrm{JMCR} / 76-03$

Publication date: February $28^{\text {th }} 2021$

\section{Introduction}

Customer reviews have become an important source of information when shoppers purchase products online (Mathwick \& Mosteller, 2017; Thakur, 2018). Consumers tend to consider customer reviews to be more credible compared to the information provided by sellers (Bickart \& Schindler, 2001; Godes \& Mayzlin, 2004; Thakur, 2018). According to a Pew Research Center survey (2018), the majority of Americans believe customer reviews improve their shopping experiences and increase their confidence in purchase decisions (Turner \& Rainie, 2020). Due to the significant role of customer reviews, marketers utilize them in order to understand customer satisfaction and to improve the relationship with their customers in online business (Hwang, Yoo, \& Orr, 2018; O’Connor, 2010).

For consumers, posting online reviews is a means to express either their satisfaction or dissatisfaction with services or products that they purchased (Maxham III \& Netemeyer, 2002; Ranaweera \& Prabhu, 2003; Thakur, 2018). Additionally, the act of posting and reading online reviews substantially constitutes customer engagement (i.e., "a psychological state of mind that leads to frequent interaction with the focal object, such as a brand or a medium", Thakur, 2018, p. 48) and also allows customers to interact with each other (Mathwick \& Mosteller, 2017; Rasool, Shah, \& Islam, 2020; Thakur, 2018). This suggests that online-review-driven customer engagement can affect purchase decisions and the relationship between customers and companies (Thakur, 2018).

Researchers have also asserted trust as another significant factor that prompts customers to post positive reviews about the services or products (Harris \& Goode, 2004; Kim, Jin, \& Swinney, 2009; Ranaweera \& Prabhu, 2003; Thakur, 2018). That means consumers are likely to post positive reviews when they receive a credible source of information on shopping sites. Therefore, it is assumed that the customer engagement with online reviews is closely related to the extent to which the website provides customers with credible sources (Hwang et al., 2018).

Website credibility is defined as a customer's perceived trust toward information of website (Dochterman \& Stamp, 2010; Fogg et al., 2001; Hwang et al., 2018). Website credibility represents a combined credibility of information provider, website contents, aesthetics, and accessibility (Alsudani \& Casey, 2009). Previous researchers have studied website credibility in consumer behavior, including factors of website credibility in eretailing (e.g., Limbu \& Jensen, 2018) and the impact of online review credibility on purchase intentions (e.g., Thomas, Wirtz, \& Weyerer, 2019). Researchers have also suggested website credibility as a determinant of customers' online purchase decisions (Hwang et al., 2018; Shareef, Kumar, \& Kumar, 2008). However, little is 
known with respect to how the extent customers are engaged in online reviews can affect the degree of website credibility that they perceive and the purchase intentions they develop, despite several studies about the relationship between website credibility and consumers' purchase intentions.

Based on the findings of aforementioned studies, we propose that the degree to which customers are engaged in online reviews varies depending on their previous experience and their level of satisfaction. Furthermore, we propose that customer engagement in online reviews might differently influence their perceived trust toward website and their purchase intentions depending on the level of customer engagement in online reviews. Customer engagement in online reviews has been broadly examined in consumer behavior research (Kim, Kim, \& Wachter, 2013; Rossmann, Ranjan, \& Sugathan, 2016; Thakur, 2018). Some consumers heavily rely on online reviews whereas some other consumers rarely do when purchasing a product or service (Thakur, 2018). This suggests that understanding the different impacts of customer engagement in online reviews is important for marketers to improve the relationship with their customers. There has been minimal research, however, regarding the influence of customer engagement in online reviews by considering the varying levels that consumers have. Therefore, the purpose of this study is to examine how website credibility and customers' purchase intentions are affected by different levels of customer engagement (i.e., low, medium, and high) in online reviews.

\section{Review of Literature}

\subsection{Source Credibility Theory}

When addressing the influences of website credibility on consumer behavior, the Source Credibility Theory (SCT) provides a theoretical background for the relationships. The SCT stemmed from a work by Hovland, Janis, and Kelley (1953), which addressed the role of information source credibility in communications and persuasion. Specifically, with high source credibility, on the one hand, individuals are generally accepting of the content of the communication and do not evaluate it critically nor do they generate counterarguments. On the other hand, with a communication from a questionable source an individual may dissociate the source from the content by disbelieving the source that delivered the communication (Hovland et al., 1953).

From the perspective of the SCT, the discounting principle is a basis for making judgments, indicating that an individual is unlikely to attribute the behavior to any particular cause when multiple credible justifications are given to the individual for a particular behavior (Kelley, 1972). The discounting principle explains trust as a factor that determines source credibility (Hovland et al., 1953). When a communicator has trusted motives, this communicator is more likely to be seen as credible by an information receiver than another communicator whose goal is to influence. The information receiver perceives that the individual with a goal to influence has a reporting bias because the message is believed to be compromised by external pressures (Eagly, Wood, \& Chaiken, 1978). In other words, when a message is viewed as being the result of external factors, the content of the message is discounted as unrepresentative of the communicator's actual views (Coleman \& Irving, 1997). For example, advertisements that claim superiority across all product characteristics prompt consumers to attribute the message content mostly to advertisers' desire to sell the product. Consequently, consumers are uncertain about the actual characteristics of the product as the claims are not different from the claims made by advertisements for competitors' products (Coleman \& Irving, 1997).

\subsection{Customer Engagement in Online Reviews}

Due to consumers' perceptions of messages provided by companies as being biased, online retailers provide objective information by using online customer reviews in hopes of generating online word-of-mouth recommendations. Word-of-mouth is one of the most influential methods of information transmission, and online customer reviews are a powerful channel to develop online word-of-mouth (Duan, Gu, \& Whinston, 2008). Consumers consider online customer reviews to be unfiltered word of mouth from other consumers (Ho-Dac, Carson, \& Moore, 2013). In contrast to messages delivered by companies which they discount, consumers are likely to consider online customer reviews to be highly credible as they believe that the information in online customer reviews is not created by the company (Ho-Dac et al., 2013). It is now a common practice of consumers visiting websites which are not associated with a certain brand, such as Amazon.com, to read customer reviews as part of their information search process before purchasing a product (Simonson \& Rosen, 2014). Therefore, online retailers strategically incorporate online customer reviews into their websites as a way to provide objective information.

In response to this frequent use of online customer reviews, marketing and consumer behavior researchers have examined the effect of the online messages utilizing the SCT. For example, drawing on the SCT, Duo et al. (2012) examined how the source of a product review influences consumers' product judgments, and found that regular internet users' reviews earned greater trust than product manufacturers' reviews. They also found that regular internet users' reviews play a significant role in helping consumers judge the credibility of online reviews. 
Additionally, researchers have recently been focused on customer engagement with online reviews (Thakur, 2018). Customer engagement "goes beyond the transactional motive of immediate purchase intention. The motives for interactions with the focal object may be utilitarian (e.g., looking for new product launch, promotional offers, deals, etc. in a specific category) with the objective of information for potential purchase in future or hedonic (e.g., looking for entertainment in new market trends, scenic pictures, etc.) with the objective of keeping oneself abreast of environment" (Thakur, 2018, p. 49). Islam and Rahman (2016) suggested that customers actively look for information by triggering conversations with brands that provoke word-of-mouth on online brand communities. They examined the role of customer engagement in brand communities on Facebook and emphasized it as a mediator between customer involvement and trust. In another study of Islam and Rahman (2017), they found that customer engagement in brand communities on Facebook is a critical factor enhancing brand loyalty. They also indicated that companies encourage their customers to participate in advertising campaigns because the interactions enhance trust towards the brand.

Based on the literature, it is speculated that customers attribute different levels of credibility to websites and online purchase intentions depending on the extent to which they are emotionally invested and interact with online reviews. It is also logical to assume that the more consumers are engaged in online reviews, the more they are likely to attribute credibility to websites. Therefore, we posit the following hypotheses:

Hypothesis 1: Website credibility is different depending on the level of customer engagement in online reviews.

Hypothesis 2: Online purchase intention is different depending on the level of customer engagement in online reviews.

Hypothesis 3: Customer engagement in online reviews positively influences website credibility.

\subsection{Website Credibility and Purchase Intentions}

Purchase intentions refer to consumer's volitional commitment to purchase a product/service online (Kim, Ferrin, \& Rao, 2009). It is crucial to encourage consumers to use a retailer's website to obtain information to, in turn, encourage them to purchase products online and actually complete the transaction (Ganguly, Dash, Cyr, \& Head, 2010). Trust has been widely used in e-commerce studies (Kim \& Peterson, 2017) and is equivalent to the concept of website credibility in this current study. Online trust is usually considered to be reliant on a specific online retailer by its stakeholders regarding the company's business activities on its website (Kim, 2012; Kim \& Peterson, 2017). Gonzlez-Benito and Martos-Partal (2012) suggested that consumer trust in an online shopping platform plays a critical role in consumers' loyalty and actual purchases on the website. Online trust is also a significant predictor that creates a positive attitude toward purchase behavior, which also results in purchase intentions (Jarvenpaa, Tractinsky, \& Vitale, 2000). Researchers have suggested that online trust directly influences online purchase intentions (Cho \& Sagynov, 2015). Researchers have also demonstrated the positive influence of website credibility on purchase intentions (Cho \& Sagynov, 2015). For example, Awad and Ragowsky (2008) found that heightened levels of trust on online retailers were related to a greater intention to shop online. The findings of the previous studies lead to a position that consumers are more likely to purchase products online when they perceive the websites to have a high level of credibility. Given the discussion above, we propose the following hypothesis:

Hypothesis 4: Website credibility positively influences online purchase intentions.

\section{Method}

3.1 Sampling and Procedure

College students were selected as the sample of this study because they are active consumers purchasing products online (Riaz \& Raman, 2015). Upon approval from the Institutional Review Board (IRB), a pilot study was conducted to identify modifications in the survey that may be needed in the main study. After the pilot study, total 403 participants (254 male and 149 female) who attended a university in the Midwest of the U.S. participated in the study. The average age of the participants was $22.3(S D=4.47)$. To recruit the participants, the authors sent out an introductory email to invite students in management and/or marketing programs of universities in the Midwest to the study. The authors also recruited the participants in the classrooms by providing them with a brief description of the study. For those who were interested in the study, an online survey link was provided via email with an extra credit opportunity in exchange for participating in the study. The students who have not purchased products online in the recent two years were excluded in the recruitment process in order to minimize the sampling bias.

\subsection{Instruments}

All item scales for variables (i.e., customer engagement with online reviews, website credibility, and online purchase intentions) were adopted and modified from previous studies (Ellison et al., 2007; Flanagin \& Metzger, 2007; Ohanian, 1990; Thakur, 2018). Each item was measured on a seven-point Likert scale $(1=$ Strongly Disagree, 7 = Strongly Agree). 
In the current study, Customer Engagement in Online Reviews refer to the extent to which customers consider online reviews when they purchase products online. Three items were adopted and modified from the Thakur's (2018) customer engagement with mobile app scale and Ellison et al.'s (2007) Facebook Intensity scale. Items included whether online consumers read online reviews and, if so, how important it is to them.

Website Credibility represents the extent to which consumers perceive that the website is trustworthy and provides online consumers with accurate and useful information. Seven items were adopted from the Flanagin and Metzger's (2007) perceived credibility of web-based information scale and Ohanian's (1990) source credibility scale. Items included whether the website is trustworthy, believable, reliable, honest, safe, accurate, and informative.

Online Purchase Intentions mean an online consumer's willingness to purchase a product online. A total of five items were adopted and modified from the Schlosser, White, and Lloyd's (2006) online purchase intention scale. Items included whether likely consumers were to return to purchase the product online in the short term and/or long term (see Table 1).

Table 1. Constructs and Scale Items

\begin{tabular}{|c|c|c|c|c|}
\hline Constructs & Items & $M$ & $S D$ & Cronbach's $\alpha$ \\
\hline \multirow{3}{*}{$\begin{array}{c}\text { Customer } \\
\text { Engagement in } \\
\text { Online Reviews }\end{array}$} & $\begin{array}{l}\text { When I shop products online, I tend to read customer } \\
\text { reviews. }\end{array}$ & 4.79 & 1.57 & 0.91 \\
\hline & Reading online customer reviews is important to me. & 4.88 & 1.58 & \\
\hline & I read customer reviews before I purchase online. & 4.71 & 1.48 & \\
\hline \multirow{7}{*}{$\begin{array}{l}\text { Website } \\
\text { Credibility }\end{array}$} & I think "ebay.com" is trustworthy. & 4.29 & 1.50 & 0.96 \\
\hline & I think "ebay.com" is believable. & 4.36 & 1.47 & \\
\hline & I think "ebay.com" is reliable. & 4.26 & 1.46 & \\
\hline & I think "ebay.com" is honest. & 4.19 & 1.40 & \\
\hline & I think "ebay.com" is safe. & 4.11 & 1.47 & \\
\hline & I think "ebay.com" is accurate. & 4.19 & 1.43 & \\
\hline & I think "ebay.com" is informative. & 4.21 & 1.43 & \\
\hline \multirow{5}{*}{$\begin{array}{c}\text { Online } \\
\text { Purchase } \\
\text { Intentions }\end{array}$} & I will return to "ebay.com" to purchase products. & 3.82 & 1.64 & 0.95 \\
\hline & $\begin{array}{l}\text { I will consider purchasing from "ebay.com" in the short } \\
\text { term. }\end{array}$ & 4.01 & 1.63 & \\
\hline & I will consider purchasing from "ebay.com" in the long term. & 3.94 & 1.70 & \\
\hline & I am likely to purchase products via "ebay.com". & 3.48 & 1.63 & \\
\hline & I am probable to purchase products via "ebay.com". & 3.51 & 1.63 & \\
\hline
\end{tabular}

\subsection{Data Analysis}

Upon completing data collection, missing data were excluded for accurate data analysis. One-way multivariate analysis of variance (MANOVA) was employed using Statistical Package for the Social Sciences (SPSS) version 27 to examine how website credibility and online purchase intentions are differently affected by the level (high/medium/low) of engagement in online reviews. In addition, regression analyses were carried out to measure causal relations among variables (i.e., customer engagement in online reviews, website credibility, and online purchase intentions).

\section{Results}

Descriptive statistics show that mean scores of website credibility and online purchase intentions according to the level of customer engagement with online reviews. As illustrated in Table 2, website credibility was the highest $(M=4.44, S D=1.32)$ when customer engagement with online reviews was high. As with website credibility, online purchase intentions were the highest $(M=4.03, S D=1.48)$ at the high level of customer engagement in online reviews (see Table 2). 
Table 2. Website Credibility and Online Purchase Intentions According to the Level of Customer Engagement in Online Reviews

\begin{tabular}{|c|c|c|c|c|c|}
\hline \multirow{2}{*}{} & & \multicolumn{2}{|c|}{ Website Credibility } & \multicolumn{2}{c|}{ Online Purchase Intentions } \\
\cline { 3 - 6 } & & $M$ & $S D$ & $M$ & $S D$ \\
\hline \multirow{3}{*}{$\begin{array}{c}\text { Customer Engagement in } \\
\text { Online Reviews }\end{array}$} & High & 4.44 & 1.32 & 4.03 & 1.48 \\
\cline { 2 - 6 } & Medium & 4.18 & 1.25 & 3.76 & 1.42 \\
\cline { 2 - 6 } & Low & 3.67 & 1.11 & 2.90 & 1.33 \\
\hline
\end{tabular}

Note. $N=403$.

The results of one-way MANOVA revealed that there were significant multivariate effects of the level of customer engagement in online reviews on website credibility and online purchase intentions, $F(4,798)=8.18$, $p<.05$; Wilk's $\Lambda=.92$, partial $\eta^{2}=.04$. Post-hoc comparisons using the Scheffe's test showed that there were group differences of website credibility between high level of engagement in online reviews $(M=4.44, S D=$ $1.32)$ and low level of engagement $(M=3.67, S D=1.11)$, and between medium level of engagement $(M=4.18$, $S D=1.25)$ and low level of engagement $(\mathrm{M}=3.67, \mathrm{SD}=1.11)$. As with website credibility, there were group differences of online purchase intentions between high level of engagement in online reviews $(M=4.44, S D=$ 1.32) and low level of engagement $(M=3.67, S D=1.11)$, and between medium level of engagement $(\mathrm{M}=4.18$, $\mathrm{SD}=1.25)$ and low level of engagement $(M=3.67, S D=1.11)$. Therefore, hypotheses one $(\mathrm{H} 1)$ and two $(\mathrm{H} 2)$ were successfully confirmed.

The results of a simple linear regression showed that customer engagement in online reviews positively predicted website credibility $(\beta=.21, \mathrm{t}(402)=4.19, p<.05)$. Website credibility also significantly predicted online purchase intentions $(\beta=.66, \mathrm{t}(402)=17.78, p<.05)$. Thus, hypotheses three $(\mathrm{H} 3)$ and four (H4) were also satisfied.

\section{Discussion}

\subsection{Theoretical Implications}

This study provides theoretical implications for understanding the role of customer engagement in online reviews in perceptions of website credibility and of online purchase intentions. Although research has widely applied the SCT in consumer behavior, empirical research has not applied the theory where customer engagement in online reviews, website credibility, and online purchase intentions were considered altogether. This study demonstrates and confirms that online reviews are a significant factor for consumers to determine how credible a website (e.g., eBay) is and for them to develop intentions to purchase products online. Online reviews help consumers learn about products and services and reduce uncertainty while increasing their confidence in their purchase (Reich \& Maglio, 2020). Therefore, consumers who are heavily engaged with customer reviews tend to trust a website more and are likely to have stronger intentions to purchase products on the website than those who are less engaged with customer reviews.

The findings also call for attention to be given to the customers who are not actively or heavily involved in online customer reviews. In the SCT, source credibility can be characterized by expertise (i.e., the degree to which an individual can provide the correct information), trustworthiness (i.e., receiver's level of message trust of the advice provided by the information provider), and homophily (i.e., the extent to which two or more people who interact are similar in certain demographic attributes) (Ismagilova, Slade, Rana, \& Dwivedi, 2020). Previous studies suggest these characteristics affect consumers' perceptions of source credibility (Chang \& Wu, 2014; Filieri, 2015; López \& Sicilia, 2014). Consumers who are not heavily engaged in online reviews may rely more on experts or their personal connections when evaluating websites and making a purchase decision. Therefore, these characteristics need to be considered in customer engagement studies in the future.

The findings also show that website credibility influences online purchase intentions in support of previous research (Awad \& Ragowsky, 2008; Cho \& Sagynov, 2015; Jarvenpaa et al., 2000). For consumers, websites are both a place to purchase a product and an information source. According to the SCT, source credibility is determined by perceived trustworthiness of the information sender (Hovland et al., 1953). Although consumers may not read online reviews on eBay, they usually review the product information provided on the website. The findings of this study confirm that consumers who trust eBay are likely to develop more intentions to purchase products on the website because they believe the information provided by eBay valid and honest.

\subsection{Practical Implications}

This study provides practical implications for marketers and managers with respect to how to develop and enhance website credibility. First, marketers and managers need to provide detailed information about the 
products on their websites in order to help their consumers have a full understanding of the product. For example, they need to provide an accurate and detailed description of the product (e.g., materials, specifications, price), information on similar products on the market, high quality photos and videos of the products, and unfiltered consumer reviews on their website. In a study of Reich and Maglio (2019), consumers tend to purchase a product if it is recommended by other consumers who have made a previous purchase mistake because consumers perceive those reviewers as an expert. That is, having various reviews ranging from negative to positive can benefit both consumers and online business.

Consumers also utilize various sources of online reviews, including the actual website where consumers purchase the product, different websites, and social media, before making a purchase. Online retailers and marketers need to identify various sources of online reviews and integrate them into their websites. They can also develop a mutually beneficial partnership with those sources. Given that many young consumers trust social media celebrities' reviews (Djafarova \& Rushworth, 2017), online retailers need to identify influential social media personalities. If those social media figures had a congruent and positive image, they could consider working with those social media celebrities as their endorser and coordinate a marketing campaign.

\subsection{Limitations and Future Research}

This study provides marketers and administrators with practical information, but there are limitations to be addressed in the future research. First, this study only collected samples from college students in the U.S. Although college students are an important consumer segment, the results of study may not be applicable to the consumers in other age groups or geographic locations. Therefore, future research should consider collecting random samples from consumers in diverse age groups that can fully represent online consumers.

Second, this study used eBay.com as an example of online shopping site to measure the influence of website credibility. Although eBay.com is a popular shopping site in the U.S., the results of study may be different for other websites. For example, individuals who prefer "Amazon.com" to "eBay.com" may provide different answers to the survey items used the study. Thus, future research should consider confounding variables, such as website preference or perceived attitude toward the website.

Finally, this study has a limitation as to behavioral intentions. This study focused on measuring purchase intentions rather than analyzing actual consumption patterns of customers. Although purchase intentions are an indicator of actual purchase, purchase intentions do not always lead to actual behaviors. For example, just because an individual has an intent to purchase a product on eBay.com, the individual may end up purchasing the product at a different location or giving up the purchase. Therefore, future research should consider measuring actual consumption patterns of customers in addition to their behavioral intentions.

\section{References}

Alsudani, F., \& Casey, M. C. (2009). The effect of aesthetics on web credibility. [Online] Available: http://epubs.surrey.ac.uk/3035/

Awad, N. F., \& Ragowsky, A. (2008). Establishing trust in electronic commerce through online word of mouth: An examination across genders. Journal of Management Information. 24(4), 101-121.

Bickart, B., \& Schindler, R. M. (2001). Internet forums as influential sources of consumer information. Journal of Interactive Marketing. 15(3), 31-40.

Chang, H. H., \& Wu, L. H. (2014). An examination of negative e-WOM adoption: Brand commitment as a moderator. Decision Support Systems. 59, 206-218.

Cho, Y. C., \& Sagynov, E. (2015). Exploring factors that affect usefulness, ease of use, trust, and purchase intention in the online environment. International Journal of Management \& Information System. 19(1), 2136.

Coleman, D. F., \& Irving, P. G. (1997). The influence of source credibility attributions on expectancy theory predictions of organizational choice. Canadian Journal of Behavioural Science. 29(2), 122-131.

Djafarova, E., \& Rushworth, C. (2017). Exploring the credibility of online celebrities' Instagram profiles in influencing the purchase decisions of young female users. Computers in Human Behavior. 68, 1-7.

Duan, W., Gu, B., \& Whinston, A. B. (2008). Do online reviews matter? An empirical investigation of panel data. Decision Support Systems. 45, 1007-1016.

Dochterman, M. A., \& Stamp, G. H. (2010). Part 1: The determination of web credibility: A thematic analysis of web user's judgments. Qualitative Research Reports in Communication. 11(1), 37-43.

Duo, X., Walden, J., Lee, S., \& Lee, J. (2012). Does source matter? Examining source effects in online product reviews. Computers in Human Behavior. 28(5), 1555-1563.

Eagly, A. H., Wood, W., \& Chaiken, S. (1978). Causal inferences about communicators and their effect on opinion change. Journal of Personality and Social Psychology. 36, 424-435.

Ellison, N. B., Steinfield, C., \& Lampe, C. (2007). The benefits of Facebook "friends:" Social capital and college students' use of online social network sites. Journal of Computer-Mediated Communication. 12(4), 1143- 
1168.

Filieri, R. (2015). What makes online reviews helpful? A diagnosticity-adoption framework to explain informational and normative influences in e-WOM. Journal of Business Research. 68(6), 1261-1270.

Flanagin, A. J., \& Metzger, M. J. (2007). The role of site features, user attributes, and information verification behaviors on the perceived credibility of web-based information. New Media \& Society. 9(2), 319-342.

Fogg, B. J., Marshall, J., Laraki, O., Osipovich, A., Varma, C., \& Fang, N. (2001). What makes web sites credible? A report on a large quantitative study. [Online] Available: https://dl.acm.org/citation.cfm?id=365037

Ganguly, B., Dash, S. B., Cyr, D., \& Head, M. (2010). The effects of website design on purchase intention in online shopping: The mediating role of trust and the moderating role of culture. International Journal of Electronic Business. 8(4/5), 302-330.

Godes, D., \& Mayzlin, D. (2004). Using online conversations to study word-of-mouth communication. Marketing Science. 23(4), 545-560.

González-Benito, Ó., \& Martos-Partal, M. (2012). Role of retailer positioning and product category on the relationship between store brand consumption and store loyalty. Journal of Retailing. 88(2), 236-249.

Harris, L. C., \& Goode, M. M. (2004). The four levels of loyalty and the pivotal role of trust: a study of online service dynamics. Journal of Retailing. 80(2), 139-158.

Ho-Dac, N. N., Carson, S. J., \& Moore, W. L. (2013). The effects of positive and negative online customer reviews: Do brand strength and category maturity matter?. Journal of Marketing. 77(6), 37-53.

Hovland, C. L., Janis, I. L., \& Kelley, H. H. (1953). Communication and persuasion. New Haven, CT: Yale University Press.

Hwang, G., Yoo, J., \& Orr, T. J. (2018). The Influence of Online Customer Reviews on Sport Consumers' Purchase Intentions: The Mediating Effect of the Perceived Credibility of Website. International Journal of Human Movement Science. 12(2), 53-68.

Islam, J. U., \& Rahman, Z. (2016). Linking customer engagement to trust and word-of-mouth on Facebook brand communities: An empirical study. Journal of Internet Commerce. 15(1), 40-58.

Islam, J. U., \& Rahman, Z. (2017). The impact of online brand community characteristics on customer engagement: An application of Stimulus-Organism-Response paradigm. Telematics and Information. 34, 96-109.

Ismagilova, E., Slade, E., Rana, N. P., \& Dwivedi, Y. K. (2020). The effect of characteristics of source credibility on consumer behavior: A meta-analysis. Journal of Retailing and Consumer Services. 53. [Online] Available: https://doi.org/10.1016/j.jretconser.2019.01.005.

Jarvenpaa, S. L., Tractinsky, N., \& Vitale, M. (2000). Consumer trust in an Internet store. Information Technology and Management. 1, 45-71.

Kelley, H. H. (1972). Attribution in social interaction. In E. E. Jones, D. E. Kanouse, H. H. Kelley, R. E. Nisbett, S. Valins, \& B. Weiner (Eds.) Attribution: Perceiving the causes of behavior (pp. 1-26). Morristown, NJ: General Learning Press.

Kim, D. J. (2012). An investigation of the effect of online consumer trust on expectation, satisfaction, and postexpectation. Information Systems and E-Business Management. 10(2), 219-240.

Kim, D. J., Ferrin, D. L., \& Rao, H. R. (2009). Trust and satisfaction, two stepping stones for successful ecommerce relationships: A longitudinal exploration. Information Systems Research. 20(2), 237-257.

Kim, J., Jin, B., \& Swinney, J. L. (2009). The role of etail quality, e-satisfaction and e-trust in online loyalty development process. Journal of Retailing and Consumer Services. 16(4), 239-247.

Kim, Y. H., Kim, D. J., \& Wachter, K. (2013). A study of mobile user engagement (MoEN): Engagement motivations, perceived value, satisfaction, and continued engagement intention. Decision Support Systems. 56, 361-370.

Kim, Y., \& Peterson, R. A. (2017). A meta-analysis of online trust relationships in e-commerce. Journal of Interactive Marketing. 38, 44-54.

Limbu, Y. B., \& Jensen, R. W. (2018). The determinants and consequences of website credibility in e-retailing: examining the roles of ethical issues. International Journal of Electronic Marketing and Retailing. 9(1), 89108.

López, M., \& Sicilia, M. (2014). Determinants of e-WOM influence: The role of consumers' internet experience. Journal of Theoretical and Applied Electronic Commerce Research. 9(1), 28-43.

Mathwick, C., \& Mosteller, J. (2017). Online reviewer engagement: A typology based on reviewer motivations. Journal of Service Research. 20(2), 204-218.

Maxham III, J. G., \& Netemeyer, R. G. (2002). A longitudinal study of complaining customers' evaluations of multiple service failures and recovery efforts. Journal of Marketing. 66(4), 57-71.

O'Connor, P. (2010). Managing a hotel's image on TripAdvisor. Journal of Hospitality Marketing \& Management. 19(7), 754-772. 
Ohanian, R. (1990). Construction and validation of a scale to measure celebrity endorsers' perceived expertise, trustworthiness, and attractiveness. Journal of Advertising. 19(3), 39-52.

Ranaweera, C., \& Prabhu, J. (2003). The influence of satisfaction, trust and switching barriers on customer retention in a continuous purchasing setting. International Journal of Service Industry Management. 14(4), 374-395.

Rasool, A., Shah, F. A., \& Islam, J. U. (2020). Customer engagement in the digital age: a review and research agenda. Current Opinion in Psychology. 36, 96-100.

Reich, T. \& Maglio, S. (2020). Featuring mistakes: The persuasive impact of purchase mistakes in online reviews. Journal of Marketing. 84(1), 52-65.

Riaz, A., \& Raman, S. (2015). The emerging trend of online shopping: A Literature review. International Journal of Accounting, Business and Management. 1(1), 1-8.

Rossmann, A., Ranjan, K. R., \& Sugathan, P. (2016). Drivers of user engagement in eWoM communication. Journal of Services Marketing. 30(5), 541-553.

Schlosser, A. E., White, T. B., \& Lloyd, S. M. (2006). Converting web site visitors into buyers: how web site investment increases consumer trusting beliefs and online purchase intentions. Journal of Marketing. 70(2), $133-148$

Shareef, M. A., Kumar, U., \& Kumar, V. (2008). Role of different electronic-commerce (EC) quality factors on purchase decision: a developing country perspective. Journal of Electronic Commerce Research. 9(2), 92.

Simonson, I., \& Rosen, E. (2014). What marketers misunderstand about online reviews. Harvard Business Review. 92(1/2), 23-25.

Thakur, R. (2018). Customer engagement and online reviews. Journal of Retailing and Consumer Services. 41, 48-59.

Thomas, M. J., Wirtz, B. W., \& Weyerer, J. C. (2019). Determinants of online review credibility and its impact on consumers' purchase intention. Journal of Electronic Commerce Research. 20(1), 1-20.

Turner, E., \& Rainie, L. (2020). Most Americans rely on their own research to make big decisions, and that often means online searches. [Online] Available: https://www.pewresearch.org/fact-tank/2020/03/05/mostamericans-rely-on-their-own-research-to-make-big-decisions-and-that-often-means-online-searches/ 